\title{
Development of a Novel Gene Silencer Pyrrole-Imidazole Polyamide Targeting Human Connective Tissue Growth Factor
}

\author{
Jian-Xin Wan,${ }^{a}$ Noboru FuKUdA, ${ }^{*}, a, b$ Takahiro Ueno, ${ }^{a}$ Takayoshi Watanabe, ${ }^{c}$ Hiroyuki Matsuda, ${ }^{b}$ \\ Kosuke Saito, ${ }^{b}$ Hiroki Nagase, ${ }^{b, c}$ Yoshiaki Matsumoto, ${ }^{d}$ and Koichi Matsumoto ${ }^{a}$ \\ ${ }^{a}$ Division of Nephrology Hypertension and Endocrinology, Department of Medicine, Nihon University School of Medicine; \\ ${ }^{c}$ Division of Cancer Genetics, Department of Advanced Medical Science, Nihon University School of Medicine; 30-1 \\ Ooyaguchi-kamimachi, Itabashi-ku, Tokyo 173-8610, Japan: ${ }^{b}$ Advanced Research Institute of the Sciences and \\ Humanities, Nihon University Graduate School; 12-5 Gobancho, Chiyoda-ku, Tokyo 102-8251, Japan: and ${ }^{d}$ Department \\ of Clinical Pharmacokinetics, School of Pharmacy, Nihon University; 7-7-1 Narashinodai, Funabashi, Chiba 274-8555, \\ Japan. Received April 8, 2011; accepted July 4, 2011; published online July 11, 2011
}

Pyrrole-imidazole (PI) polyamide can bind to specific sequences in the minor groove of double-helical DNA and inhibit transcription of the genes. We designed and synthesized a PI polyamide to target the human connective tissue growth factor (hCTGF) promoter region adjacent to the Smads binding site. Among coupling activators that yield PI polyamides, 1-[bis(dimethylamino)methylene]-5-chloro-1H-benzotriazolium 3-oxide hexafluorophosphate (HCTU) was most effective in total yields of PI polyamides. A gel shift assay showed that a PI polyamide designed specifically for hCTGF (PI polyamide to hCTGF) bound the appropriate double-stranded oligonucleotide. A fluorescein isothiocyanate (FITC)-conjugated PI polyamide to CTGF permeated cell membranes and accumulated in the nuclei of cultured human mesangial cells (HMCs) and remained there for $48 \mathrm{~h}$. The PI polyamide to hCTGF significantly decreased phorbol 12-myristate acetate (PMA)- or transforming growth factor- $\beta 1$ (TGF- $\beta 1$ )-stimulated luciferase activity of the hCTGF promoter in cultured HMCs. The PI polyamide to hCTGF significantly decreased PMA- or TGF- $\beta 1$-stimulated expression of hCTGF mRNA in a dose-dependent manner. The PI polyamide to hCTGF significantly decreased PMA- or TGF- $\beta 1$-stimulated levels of hCTGF protein in HMCs. These results indicate that the developed synthetic PI polyamide to hCTGF could be a novel gene silencer for fibrotic diseases.

Key words pyrrole-imidazole polyamide; connective tissue growth factor; promoter activity; Fmoc method; gene therapy; human

Connective tissue growth factor (CTGF) is a potent growth factor that induces fibroblast proliferation, extracellular matrix (ECM) production, angiogenesis, migration and adhesion, and its overproduction is known to lead to tissue fibrosis. ${ }^{1,2}$ CTGF has also been implicated in the pathogenesis of fibrotic diseases. ${ }^{3-5)}$

Pyrrole-imidazole (PI) polyamides are small synthetic molecules composed of the aromatic rings of the $\mathrm{N}$ methylpyrrole and $N$-methylimidazole amino acids. ${ }^{6-8)}$ Synthetic polyamides can bind to specific nucleotide sequences in the minor groove of double-helical DNA with high affinity and specificity, suggesting that PI polyamides could be useful tools for molecular biology and, potentially, medicine. Binding site specificity is dependent on the side-by-side pairing of pyrrole (Py) and imidazole (Im): the Py/Im pair targets the CG base pair, Im/Py recognizes the GC base pair, and Py/Py binds both AT and TA base pairs. ${ }^{6,7)}$ Transcriptional regulation is essential for gene expression. Initiation of transcription requires binding of transcription factors to the cognate DNA response elements in the gene promoter. PI polyamides bind the minor groove; hence they block binding of transcription factors that inhibit gene expression.

We have developed PI polyamides targeting transforming growth factor- $\beta 1$ (TGF- $\beta 1$ ) and demonstrated that they significantly inhibited gene expression of TGF- $\beta 1$ in vitro and in vivo. ${ }^{9,10)}$ Thus, the synthetic PI polyamides should serve as gene silencers in medical applications. However, the synthesis methods for PI polyamides have previously required a high level of technology, a complicated operation, and a long production period. We have developed a novel automatic synthesis method for PI polyamides with a high yield in a more stable manner. In the current study, we designed and synthesized PI polyamide targeting human CTGF by the novel high-efficient Fmoc solid-phase method, and examined the distribution and effects of the PI polyamide to hCTGF on CTGF gene expression.

\section{MATERIALS AND METHODS}

Designing and Synthesis of PI Polyamide Targeting the hCTGF Promoter The structure of the PI polyamide used in this study is shown in Fig. 1. The PI polyamide was designed to bind $\mathrm{bp}-157$ to -151 of the hCTGF promoter adjacent to the Smad binding site (Figs. 1A-C). Mismatch polyamide was designed to not bind to the transcription sites of the promoter (Fig. 1D). The hCTGF promoter contains Smad binding sites and AP1 binding sites. Smad proteins are pivotal intracellular mediators of the TGF- $\beta$ family. AP-1 elements respond to AP-1 transcription factors such as phorbol 12-myristate acetate (PMA), Jun homodimers or Fos/Jun heterodimers, angiotensin II, and v-Src. Stimulation of hCTGF promoter activity occurs by TGF- $\beta 1$ or PMA.

Machine-assisted automatic synthesis of PI polyamides was performed with a Pioneer ${ }^{\mathrm{TM}}$ continuous-flow peptide synthesizer (Applied Biosystems, Foster City, CA, U.S.A.) on a $0.1 \mathrm{mmol}$ scale $(200 \mathrm{mg}$ of Fmoc- $\beta$-alanine-CLEAR Acid Resin, $0.50 \mathrm{meq} / \mathrm{g}$, Peptide Institute, Osaka, Japan). Automatic solid phase synthesis was undertaken with the following series of steps: washing with dimethylformamide (DMF); removal of the Fmoc group with 20\% piperidine/DMF; washing with methanol; coupling with a monomer in the presence of 1-[bis(dimethylamino)methyl- 
A $\quad-177$

5'-TTTTCAGACGGAGGAATGCTGAGTGTCAAGGG GT-3'

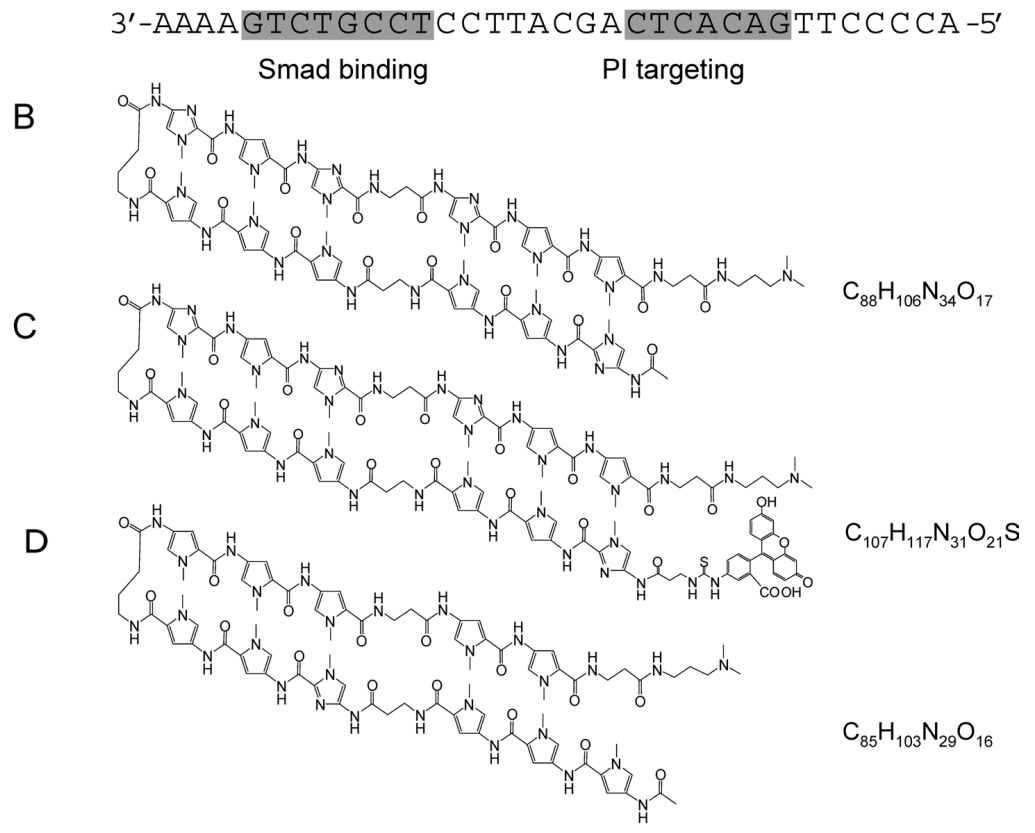

Fig. 1. Structure and Target Sequence of the Pyrrole-Imidazole (PI) Polyamide Targeting hCTGF Promoter

(A) PI polyamide was designed to bind bp -157 to -151 of the hCTGF promoter adjacent to the Smad binding site. (B) Structure of the hCTGF promoter-specific PI polyamide. (C) Structure of the FITC-labeled PI polyamide targeting hCTGF. (D) Structure of the mismatch polyamide.

ene]-5-chloro-1H-benzotriazolium 3-oxide hexafluorophosphate (HCTU) and diisopropylethylamine (4 eq each) for $60 \mathrm{~min}$; washing with methanol; protection with acetic anhydride/pyridine; and a final DMF washing step. The coupling was also performed in the presence of $O$-[7-azobenzotriazol1-yl]-1,1,3,3-tetramethyluronium hexafluorophosphate (HATU) or 2-[1H-benzotriazol-1-yl]-1,1,3,3-tetramethyluronium hexafluorophosphate (HBTU) as another activators. After removal of the Fmoc group from the Fmoc- $\beta$-alanine-Wang resin, the resin was washed successively with methanol. The coupling step was performed with Fmoc-amino acid followed by a washing with methanol. These steps were repeated until the entire sequencing was complete. After the coupling steps were completed, the N-terminal amino group was protected or coupled with fluorescein isothiocyanate (FITC) and washed with DMF, and the reaction vessel was drained. The synthetic polyamides were isolated after the cleavage step ( $5 \mathrm{ml}$ of $91 \%$ trifluoroacetic acid (TFA)-3\% triisopropylsilane (TIS)-3\% 5 dimethylsulfide (DMS)-3\% water/0.1 mmol resin) by cold ethyl ether precipitation. The synthetic polyamides were isolated after the cleavage step $(5 \mathrm{ml}$ of $N, N$-dimethylaminopropylamine $/ 0.1 \mathrm{mmol}$ resin, $50^{\circ} \mathrm{C}$ overnight) by cold ethyl ether precipitation. Polyamides were purified by high performance liquid chromatography (HPLC) with a PU-980 HPLC pump, a UV-975 HPLC UV/VIS detector (Jasco, Easton, MD, U.S.A.), and a Chemcobound 5-ODS-H column (Chemco Scientific, Osaka Japan).

Cell Culture and Distribution of PI Polyamide Human mesangial cells (HMCs) were purchased from Cambrex (Cambrex Bio Science Walkersville, Walkersville, MD, U.S.A.). HMCs were maintained in RPMI 1640 (SigmaAldrich, MO, U.S.A.) with 10\% fetal bovine serum (FBS) (Gibco Life Technologies, MD, U.S.A.) and $0.05 \mathrm{mg} / \mathrm{ml} \mathrm{Gen-}$ tamycin (Invitrogen, CA, U.S.A.). Experiments were performed on cells between the 5th and 10th passages. To examine the distribution of the PI polyamide to hCTGF in cells, HMCs were incubated with $1 \mathrm{nmol} / 1$ FITC-conjugated PI polyamide in RPMI 1640 for $48 \mathrm{~h}$.

CTGF Promoter Activity A 2.2-kb fragment of the hCTGF promoter was inserted into pGL3-basic vector (pGL3-CTGF) (Promega, Madison, WI, U.S.A.). One microgram of pGL3-CTGF was transfected into HMCs in serumfree medium with the lipofectamine reagent for $4 \mathrm{~h}$. Twentyfour hours after transfection, cells were incubated with $1 \mu \mathrm{mol} / 1 \mathrm{PI}$ polyamide to hCTGF in the presence or absence of $1 \mu \mathrm{mol} / 1$ PMA or $5 \mathrm{ng} / \mathrm{ml}$ TGF- $\beta 1$ (Sigma) in RPMI 1640 containing $0.5 \%$ calf serum for $24 \mathrm{~h}$. Luciferase activity was measured by the Dual-Luciferase reporter gene assay system (Promega).

Gel Mobility Shift Assay $\gamma-{ }^{32}$ P-labeled DNA corresponding to bp -175 to -144 of the human CTGF promoter (32 bp) were synthesized for gel mobility shift assays. A single-strand DNA (ssDNA) and a double-strand DNA (dsDNA) was labelled with $\left[\gamma_{-}{ }^{32} \mathrm{P}\right]$-dATP by T4 polynucleotide kinase (Promega) according to the standard method. The labelled dsDNA (10 pmol/1) was incubated with PI polyamide to hCTGF or mismatch polyamide $(10 \mathrm{nmol} / \mathrm{l})$ at $28^{\circ} \mathrm{C}$ overnight. Meanwhile, the labelled dsDNA (10 pmol/l) was incubated with PI polyamides targeting hCTGF $(10 \mathrm{nmol} / \mathrm{l})$ and unlabelled competitor dsDNA (100 or $1000 \mathrm{pmol} / \mathrm{l})$ at $28^{\circ} \mathrm{C}$ overnight. These ssDNA and dsDNA binding PI polyamide complexes were separated by electrophoresis on $20 \%$ polyacrylamide gels for $5 \mathrm{~h}$. The gels were dried for $2 \mathrm{~h}$ and exposed to X-ray film at $-80^{\circ} \mathrm{C}$ overnight.

Reverse Transcription-Polymerase Chain Reaction 
(RT-PCR) Analysis Total RNA was extracted from cultured HMCs by using ISOGEN (Nippon Gene, Toyama, Japan) according to the manufacturer's instructions. Aliquots of total RNA were reverse transcribed into single-stranded cDNA by incubation with avian myeloblastoma virus reverse transcriptase (Takara Biochemicals, Osaka, Japan). Diluted cDNA products were then subjected to PCR. The 194-bp CTGF mRNA PCR products was amplified by using the sense primer ( $5^{\prime}$-CCTGGTCCAGACCACAGAGT-3') and antisense primer (5'-TGGAGATTTTGGGAGTACGG-3'). Human 18S ribosomal RNA was used as an internal control. Amplifications were done at $95^{\circ} \mathrm{C}$ for $30 \mathrm{~s}, 55^{\circ} \mathrm{C}$ for $30 \mathrm{~s}$ and $72^{\circ} \mathrm{C}$ for $30 \mathrm{~s}$ with a GenAmp PCR System 2700 machine (Applied Biosystems) for 35 cycles. The quality and concentration of amplified PCR products were determined using the Agilent 2100 Bioanalyzer (Agilent, Palo Alto, CA, U.S.A.).

Western Blot Analysis for hCTGF Protein HMCs were disrupted with lysis buffer $(50 \mathrm{mmol} / 1$ Tris $-\mathrm{HCl}[\mathrm{pH}$ 8.0], $150 \mathrm{mmol} / 1 \mathrm{NaCl}, 0.02 \%$ sodium azide, $100 \mu \mathrm{g} / \mathrm{ml}$ phenylmethylsulfonyl fluoride, $1 \mu \mathrm{g} / \mathrm{ml}$ aprotinin, $1 \%$ Triton $\mathrm{X}-100)$. Total proteins were extracted and purified with $100 \mu \mathrm{l}$ of chloroform and $400 \mu \mathrm{l}$ of methanol. Protein concentration was determined using a dye-binding protein assay kit (Bio-Rad) as described in the manufacturer's manual. Equal amounts of protein samples were heated at $95^{\circ} \mathrm{C}$ for $5 \mathrm{~min}$ and subjected to electrophoresis on 7.5\% sodium dodecyl sulfate (SDS)-polyacrylamide gels and electroblotted onto PVDF membranes (Amersham Pharmacia Biotech, Uppsala, Sweden). Blots were incubated with mouse monoclonal anti-human CTGF C-terminal peptide antibody (R\&D Systems, Inc.) or mouse monoclonal antibody specific for $\alpha$ tubulin (Sigma) as an internal control, and were then incubated with goat anti-mouse immunoglobulin G (IgG) (BioRad). Bound antibodies were detected by enhanced chemiluminescence (ECL kit, Amersham Biosciences) and exposure to X-ray films. SDS-polyacrylamide gel electrophoresis (PAGE) molecular weight markers (Prestained SDS-PAGE Standard Broad Range, Bio-Rad Laboratories) were run to calibrate the gel. Bands were scanned and quantitated by densitometry using NIH Image software (NIH Image 1.63f).

Statistical Analysis Values are reported as mean \pm standard error (S.E.). Statistical analysis was done with Student's $t$-test for unpaired data or with two-way analysis of variance (ANOVA) or Duncan's multiple range test. $p<0.05$ was considered statistically significant.

\section{RESULTS}

Comparison of Coupling Activators in Fmoc Solid Phase Synthesis To determine the most efficient coupling activator to yield PI polyamides, we compared three activators as HATU, HBTU and HCTU. The one step coupling yields are shown in Table 1. HCTU was the most effective activator in Py-Py coupling. HATU was the most effective activator in Py-Im and Im-Im coupling. Therefore, in terms of total yield of PI polyamides full length synthesizes, using HCTU was the most effective.

Binding of PI Polyamide to Double-Stranded Oligonucleotides A gel shift assay allowed the determination of the binding affinity and specificity of polyamides for double-
Table 1. Comparison of Efficientcy of Coupling Activators in Fmoc SolidPhase Synthesis

\begin{tabular}{lcccc}
\hline \hline \multirow{2}{*}{ Activator } & \multicolumn{3}{c}{ Coupling yield (\%) } & \multirow{2}{*}{$\begin{array}{c}\text { Total yield } \\
(\%)\end{array}$} \\
\cline { 2 - 4 } & Py-Py & Py-Im & Im-Im & \\
\hline HATU & $92.8 \pm 3.5$ & $86.7 \pm 0.5$ & $75.7 \pm 1.2$ & $17.3 \pm 4.3$ \\
HBTU & $91.2 \pm 0.4$ & $87.1 \pm 1.0$ & $55.4 \pm 7.0$ & $24.2 \pm 2.0$ \\
HCTU & $96.9 \pm 0.8$ & $80.8 \pm 6.0$ & $50.0 \pm 7.9$ & $30.8 \pm 3.1$ \\
\hline
\end{tabular}

Fmoc solid-phase machine-assisted automatic synthesis of pyrrole (Py)-imidazole (Im) polyamides was performed in the presence of coupling activator as of $\mathrm{O}$-[7azobenzotriazol-1-yl]-1,1,3,3-tetramethyluronium hexafluorophosphate (HATU) or 2 [1H-benzotriazol-1-yl]-1,1,3,3-tetramethyluronium hexafluorophosphate (HBTU) or 1[bis(dimethylamino)methylene]-5-chloro- $1 H$-benzotriazolium 3-oxide hexafluorophosphate (HCTU).

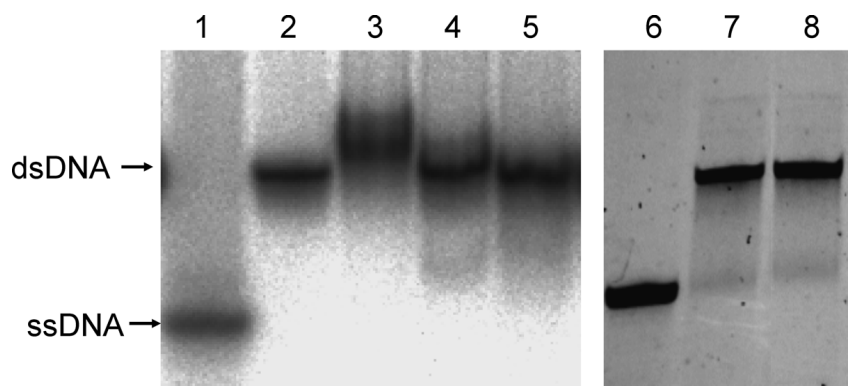

Fig. 2. Gel Shift Assay

A dsDNA fragment corresponding to $b p-175$ to -144 of the hCTGF promoter was labelled with $\left[\gamma_{-}{ }^{32} \mathrm{P}\right]$-dATP. Labelled dsDNA $(10 \mathrm{pmol} / 1)$ was then incubated with $10 \mathrm{nmol} / 1$ pyrrole-imidazole (PI) polyamide to hCTGF or mismatch polyamide $(10 \mathrm{nmol} / 1)$. Meanwhile, $10 \mathrm{pmol}$ labelled dsDNA was incubated with $10 \mathrm{nmol} / 1 \mathrm{PI}$ polyamides to hCTGF and 100 or $1000 \mathrm{pmol} / \mathrm{l}$ unlabelled competitor dsDNA. These ssDNA and dsDNA binding PI polyamide complexes were separated by electrophoresis on $20 \%$ polyacrylamide gels and visualized by autoradiography. Lane 1: labelled ssDNA; lane 2: labelled dsDNA; lane 3: $10 \mathrm{pmol}$ labelled dsDNA incubated with $10 \mathrm{nmol} / 1$ PI polyamide to hCTGF; lane $4: 10 \mathrm{pmol} / 1$ labelled dsDNA incubated with $10 \mathrm{nmol} / 1 \mathrm{PI}$ polyamide to hCTGF and $100 \mathrm{pmol} / 1$ unlabelled competitor dsDNA; lane 5: $10 \mathrm{pmol} / 1$ labelled dsDNA incubated with $10 \mathrm{nmol} / 1$ PI polyamide to hCTGF and $1000 \mathrm{pmol} / 1$ unlabelled competitor dsDNA; lane 6: labelled ssDNA; lane 7: labelled dsDNA; and lane 8: 10 pmol labelled dsDNA incubated with $10 \mathrm{nmol} / 1$ mismatch polyamide.

stranded DNA. The PI polyamide designed specifically for the hCTGF protein bound the appropriate $32 \mathrm{bp}$ doublestranded oligonucleotide, whereas the addition of unlabelled competitor dsDNA decreased the intensity of the band in a dose-dependent manner, whereas the mismatch polyamide did not show binding (Fig. 2).

Distribution of PI Polyamide in Cultured HMCs When HMCs were incubated with $1 \mu \mathrm{mol} / 1$ FITC-labelled PI polyamide to hCTGF for $2 \mathrm{~h}$, strong fluorescent signals were detected in nuclei of almost HMSc (Fig. 3). The intensity of the fluorescent signal was maintained in the nuclei for more than $48 \mathrm{~h}$.

Effect of PI Polyamide on hCTGF Promoter Activity The effect of PI polyamide on hCTGF promoter activity was analyzed by a luciferase assay. One micromolar per litter PMA or $5 \mathrm{ng} / \mathrm{ml}$ TGF- $\beta 1$ significantly increased luciferase activity in HMCs transfected with pGL3-CTGF. PI polyamide to hCTGF $(1 \mu \mathrm{mol} / 1)$ significantly decreased $(p<0.05)$ luciferase activity in cultured HMCs (Fig. 4).

Effect of PI Polyamide on Expression of hCTGF mRNA in Cultured HMCs Incubation of the HMCs with $1 \mu \mathrm{mol} / 1 \mathrm{PMA}$ for $12 \mathrm{~h}$ significantly $(p<0.05)$ increased expression of hCTGF mRNA. Doses of 0.1 and $1.0 \mu \mathrm{mol} / 1 \mathrm{PI}$ polyamides to hCTGF significantly $(p<0.05)$ decreased the 
levels of PMA-stimulated hCTGF mRNA in a dose-dependent manner (Fig. 5A), whereas $1.0 \mu \mathrm{mol} / 1$ mismatch polyamide had no effect on the level of PMA-stimulated hCTGF mRNA (Fig. 5B). Incubation of the HMCs with $5 \mathrm{ng} / \mathrm{ml}$ TGF- $\beta 1$ for $6 \mathrm{~h}$ significantly $(p<0.05)$ increased expression of hCTGF mRNA. Doses of 0.1 and $1.0 \mu \mathrm{mol} / 1$ PI polyamide to hCTGF significantly $(p<0.05)$ decreased the levels of TGF- $\beta 1$-stimulated hCTGF mRNA in a dosedependent manner (Fig. 5C).

Effect of PI Polyamide on Expression of hCTGF Proteins in Cultured HMCs Incubation of the HMCs with $1 \mu \mathrm{mol} / 1 \mathrm{PMA}$ for $12 \mathrm{~h}$ or with $5 \mathrm{ng} / \mathrm{ml} \mathrm{TGF}-\beta 1$ for $6 \mathrm{~h}$ significantly $(p<0.05)$ increased abundances of hCTGF protein (Figs. 6A, B). A dose of $1 \mu \mathrm{mol} / 1$ PI polyamide to hCTGF significantly $(p<0.05)$ decreased the level of PMA- or TGF$\beta 1$-stimulated hCTGF protein (Figs. 6A, B).

\section{DISCUSSION}

To develop a novel gene-silencing therapy for fibrotic and
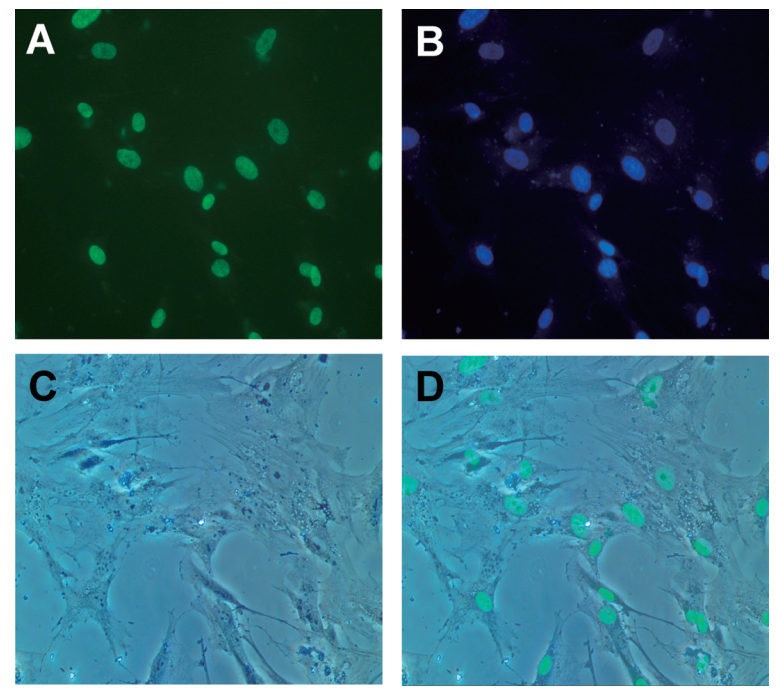

Fig. 3. Distribution of Pyrrole-Imidazole (PI) Polyamide Targeting the hCTGF Promoter in Cultured Human Mesangial Cells (HMCs)

HMCs were incubated with $1 \mathrm{nmol} / 1$ FITC-conjugated PI polyamide for $2 \mathrm{~h}$. (A) FITC conjugated PI polyamides (green) were localized in nuclei of HMCs. (B) Nuclei were stained by Hoechst 33324. (C) Bright field. (D) FITC conjugated PI polyamides were localized in nuclear region when bright fields were merged.

A
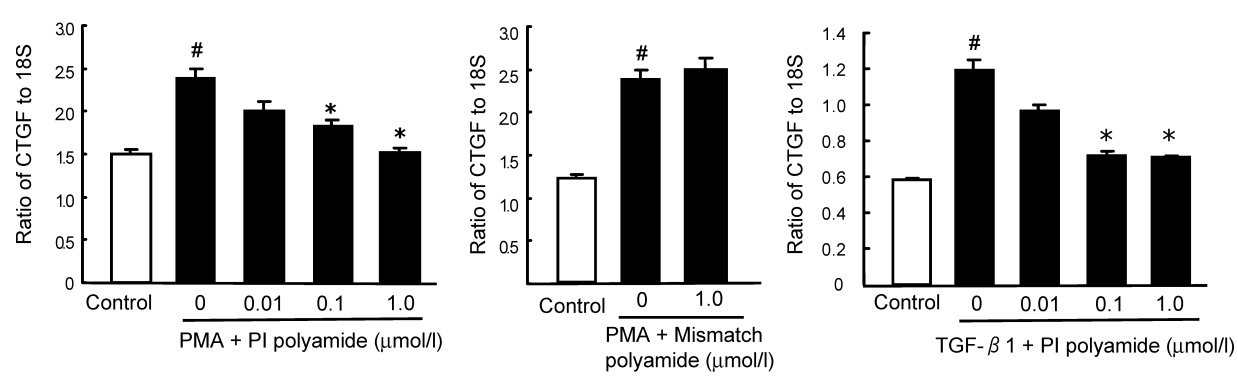

\section{C}

connective tissue proliferative diseases, such as renal sclerosis, pulmonary fibrosis, liver cirrhosis or atherosclerosis, we designed and synthesized a PI polyamide targeting hCTGF. Since polyamides are completely resistant to nucleases, they can be delivered into organs without delivery systems. In the present study, FITC-conjugated PI polyamide permeated cell membranes and accumulated and remained in the nuclei of cultured HMCs. This suggests that the PI polyamide exhibited greater permeability and stability without any vector or delivery reagents in cultured human HMCs compared with our previous observations of the cellular distributions of antisense oligonucleotides and ribozymes. ${ }^{11,12)}$ Nucleic acid medicines such as antisense DNA, ribozymes, and decoy DNA have been developed previously as gene-silencing agents. Decoy DNA, in particular, inhibits the binding of target transcription factors in a manner similar to polyamides. However, because these agents are degraded easily by nucleases, they require drug-delivery systems for sufficient distribution into organs. PI polyamides would thus be more feasible gene-silencing medicines.

PI polyamides have been synthesized by a liquid-phase method or a solid-phase Fmoc method in the presence of a

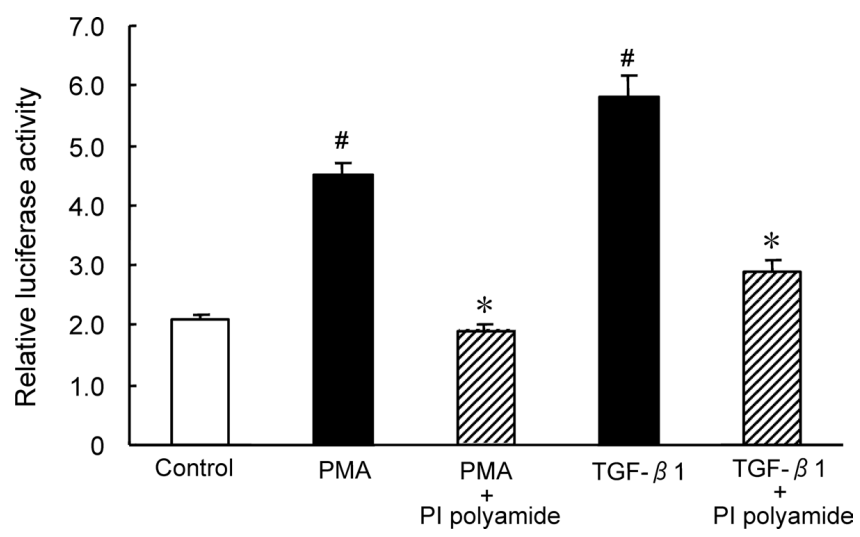

Fig. 4. Effects of Pyrrole-Imidazole (PI) Polyamide Targeting hCTGF on hCTGF Promoter Activity

A 2.2-kb fragment of the hCTGF promoter was inserted into pGL3-basic vector (pGL3-hCTGF). One microgram of pGL3-hCTGF was transfected into HMCs with lipofectamine reagent for $4 \mathrm{~h}$. Twenty-four hours after transfection, cells were incubated with $1 \mathrm{nmol} / 1 \mathrm{PI}$ polyamide targeting hCTGF promoter in the presence or absence of $1 \mu \mathrm{mol} / 1 \mathrm{PMA}$ and $5 \mathrm{ng} / \mathrm{ml}$ TGF- $\beta 1$. Luciferase activity was measured by the Dual-Luciferase reporter gene assay system. Data are shown as the mean \pm S.E. $(n=6)$. ${ }^{\prime} p<0.05$ $v s$. control cells, $* p<0.05$ vs. respective cells without PI polyamide.

Fig. 5. Effects of Pyrrole-Imidazole (PI) Polyamide Targeting hCTGF on Expression of hCTGF mRNA in Human Mesangial Cells (HMCs) in the Presence or Absence of Phorbol 12-Myristate 13-Acetate (PMA) or TGF- $\beta 1$

RT-PCR analysis of expression of hCTGF mRNA with $0.01,0.1$ and $1.0 \mu \mathrm{mol} / 1 \mathrm{PI}$ polyamide (A) or $1.0 \mu \mathrm{mol} / 1$ mismatch polyamide (B) in the presence or absence of $1 \mu \mathrm{mol} / 1$ PMA. The ratios of hCTGF mRNA to $18 \mathrm{~S}$ rRNA were evaluated by analysis of the concentration of amplified PCR products. (C) RT-PCR analysis of expression of hCTGF mRNA with $0.01,0.1$ and $1.0 \mu \mathrm{mol} / 1$ PI polyamide in the presence or absence of $5 \mathrm{ng} / \mathrm{ml} \mathrm{TGF-} \beta 1$. The ratios of hCTGF mRNA to $18 \mathrm{~S}$ rRNA were evaluated by analysis of concentration of amplified PCR products. Data are shown as the mean \pm S.E. $(n=6)$. $\# p<0.05 v s$. control cells and cells with PI polyamide $(0.01,0.1,1 \mu$ mol/1), $* p<0.05 v s$. PMA- or TGF- $\beta 1$ stimulated cells without PI polyamide. 
A
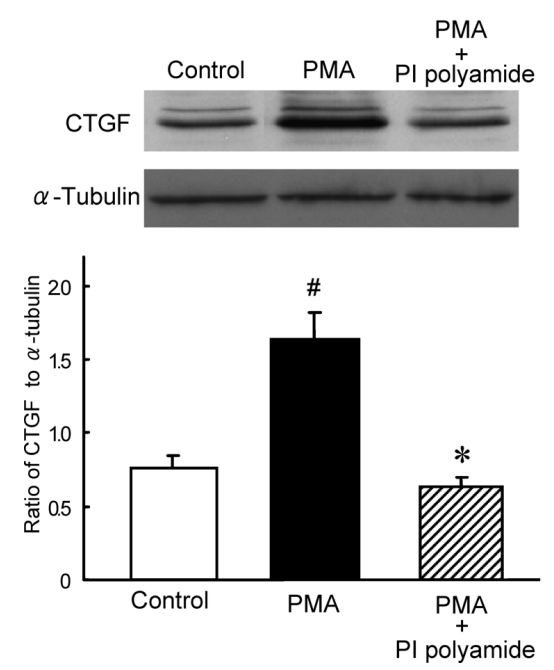

B
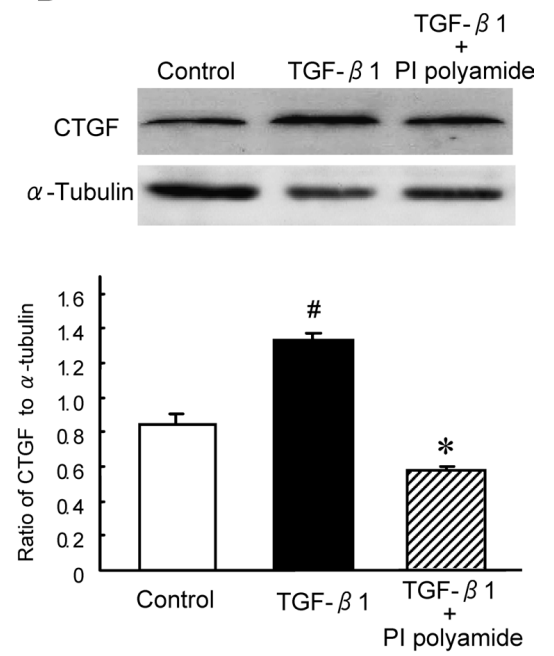

Fig. 6. Effects of Pyrrole-Imidazole (PI) Polyamide Targeting hCTGF Promoter on Production of hCTGF Protein in Human Mesangial Cells (HMCs)

HMCs were incubated with $1 \mu \mathrm{mol} / 1$ PI targeting hCTGF promoter in the presence or absence of $1 \mu \mathrm{mol} / 1 \mathrm{PMA}$ (A) or $5 \mathrm{ng} / \mathrm{ml}$ TGF- $\beta 1$ (B). The ratios of hCTGF protein to $\alpha$-tubulin were evaluated by densitometry. Data are shown as the mean $\pm \mathrm{SE}(n=4)$. $\# p<0.05 v$ s. control cells, $* p<0.05 v s$. cells with PMA or TGF- $\beta 1$.

coupling activator HATU or HBTU. These methods require a high technical input, a complicated operation, and a long production period. Moreover, these methods have not enabled fully-automated synthesis due to the presence of many steps that require manual intervention. We therefore developed a novel automatic synthesis method for PI polyamides with a high yield in a more stable manner. We have found that automated synthesis of PI polyamides, which can be promoted by using HCTU as a condensation-activator in the Fmoc solid-phase synthesis method and that PI polyamides complementing any sequence can be synthesized by combining the automated synthesis with a manual synthesis using an acid chloride. Total yield was the highest with HCTU compared to other activators. In this study, HCTU was the most effective activator in Py-Py coupling and the most effective in terms of total yield of PI polyamides full-length synthesizes. In addition, HCTU has a lower cost than the other 2 activators and is commercially available. Thus, HCTU is considered to be the most suitable condensation-activator in the Fmoc solid-phase method for PI polyamide synthesis.

Studies of PI polyamides have recently focused on the structural characterization of transcription factor-DNA complexes in promoter sequences. ${ }^{10,13)}$ The hCTGF gene promoter contains several regulatory elements, such as Smad, AP1, TATA, NF- $\kappa$ B, GATA, CBP and Oct-1. ${ }^{14-17)}$ We designed a PI polyamide specific for bp -157 to -151 of the hCTGF promoter sequence. The target region of this polyamide is located immediately adjacent to the Smad binding site in the hCTGF promoter. Recent studies have revealed that Smad proteins are pivotal intracellular mediators of the TGF- $\beta$ family. ${ }^{18,19)}$

In addition, there are two AP-1 binding sites in the hCTGF promoter. We used PMA or PMA combined with PI polyamide to treat HMCs. The result showed that the levels of CTGF mRMA and protein were increased by PMA and decreased by PI polyamide. Because the expression of most mammalian genes is likely to depend on the combined action of numerous proteins bound to promoter and enhancer sequences, it is likely that the PI polyamide specific for the
hCTGF promoter non-specifically blocks transcription factor binding in the region of the Smad element and AP-1 and thus inhibits hCTGF promoter activity. Other factors, such as chromatin packing, polyadenylation, splicing, mRNA stability, and translation initiation could influence gene expression. $^{20-23)}$ Synthetic PI polyamides can access their target sites in the nucleosome and may influence chromatin structure. $^{24,25)}$

FITC-conjugated PI polyamide permeated cell membranes and accumulated and remained in all nuclei of cultured human HMCs. In comparison with our previous observations of the cellular distributions of antisense oligonucleotides and ribozymes, ${ }^{11,12)}$ the PI polyamide exhibited greater permeability and stability in cultured human HMCs. Since polyamides are completely resistant to nucleases and can be delivered into organs without delivery systems, polyamides will be more feasible gene silencing medicines.

The PI polyamide targeting hCTGF bound strongly to the dsDNA of the hCTGF promoter region. In HMCs, PI polyamide suppressed the PMA- and TGF- $\beta 1$-stimulated hCTGF promoter activity as well as the expression of hCTGF mRNA and protein to basal levels. Thus, PI polyamides targeted to specific promoter sequences have the ability to normalize stimulated gene expression, indicating that PI polyamides show an advantage by functioning as gene-silencers rather than as the gene knockdown agents observed with siRNA. It is possible that PI polyamides will be a feasible treatment to normalize over stimulated molecules that are responsible for diseased states and will provide the additional benefit of reduced side effects.

Because polyamides can be readily synthesized and designed to target any sequence of interest, they may be useful in studies of genome function and eventually in gene silencing therapies. For example, it has been reported that polyamides open the heterochromatic brown satellite to allow binding of GAGA factor, resulting in a phenotypic change in Drosophila melanogaster. It is believed that gene silencing occurs via inhibition of gene expression once the PI polyamide has bound to a regulatory sequence. Therefore, 
the inhibition of transcription by PI polyamides at coding regions is difficult because the polyamides are removed from duplex DNA during transcription. Recently, Shinohara et al. demonstrated sequence specific gene silencing in mammalian cells by alkylating PI polyamides. ${ }^{26)}$ Extensive inhibition of gene expression by alkylating PI polyamides that target a coding region is a powerful tool for gene suppression therapy for cancers or viral infections. In contrast, inhibition of gene expression by non-alkylating PI polyamides that target a regulatory sequence is more physiological because this method abolishes the enhancing effect of the targeted transcription factor and preserves the basic expression of the target gene. Suppression of gene expression by non-alkylating polyamides should be a more efficient method for the therapy of chronic non-malignant disease.

As gene-suppressive agents, nucleic acid medicines such as antisense DNA, ribozymes and specific siRNA are easily degraded by nucleases in vivo. However, PI polyamides are chemical compounds that are resistant to nucleases. Therefore, it is possible that PI polyamides could be used as novel, orally administrated gene therapy agents. In conclusion, the developed synthetic PI polyamide designed to bind the hCTGF promoter inhibited both hCTGF gene and protein expression, suggesting that the PI polyamides may act as novel gene silencers for treatment of CTGF-related fibrotic diseases.

Acknowledgments This work was supported in part by a Grant-in-Aid for the High-Tech Research Center from the Ministry of Education, Culture, Sports, Science and Technology of Japan and by the Nihon University Multidisciplinary Research Grant, the Academic Frontier Project for Private Universities.

\section{REFERENCES}

1) Frazier K., Williams S., Kothapalli D., Klapper H., Grotendorst G. R.,
J. Invest. Dermatol., 107, 404-411 (1996).

2) Riser B. L., Denichilo M., Cortes P., Baker C., Grondin J. M., Yee J., Narins R. G., J. Am. Soc. Nephrol., 11, 25-38 (2000).

3) Grotendorst G. R., Cytokine Growth Factor Rev., 8, 171-179 (1997).

4) Lau L. F., Lam S. C., Exp. Cell Res., 248, 44-57 (1999).

5) Gupta S., Clarkson M. R., Duggan J., Brady H. R., Kidney Int., 58, 1389-1399 (2000)

6) Trauger J. W., Baird E. E., Dervan P. B., Nature (London), 382, 559561 (1996).

7) White S., Baird E. E., Dervan P. B., Chem. Biol., 4, 569-578 (1997).

8) Dervan P. B., Bioorg. Med. Chem., 9, 2215-2235 (2001).

9) Lai Y. M., Fukuda N., Ueno T., Matsuda H., Saito S., Matsumoto K., Ayame H., Bando T., Sugiyama H., Mugishima H., Serie K., J. Pharmacol. Exp. Ther, 315, 571-575 (2005).

10) Matsuda H., Fukuda N., Ueno T., Tahira Y., Ayame H., Zhang W., Bando T., Sugiyama H., Saito S., Matsumoto K., Mugishima H., Serie K., J. Am. Soc. Nephrol., 17, 422-432 (2006).

11) Fukuda N., Kubo A., Watanabe Y., Nakayama T., Soma M., Izumi Y., Kanmatsuse K., J. Hypertens., 15, 1123-1136 (1997).

12) Kotani M., Fukuda N., Ando H., Hu W. Y., Kunimoto S., Saito S., Kanmatsuse K., Cardiovasc. Res., 57, 265-276 (2003).

13) Hochhauser D., Kotecha M., O'Hare C., Morris P. J., Hartley J. M., Taherbhai Z., Harris D., Forni C., Mantovani R., Lee M., Hartley J. A., Mol. Cancer Ther., 6, 346-354 (2011).

14) Grotendorst G. R., Okochi H., Hayashi N., Cell Growth Differ, 7, $469-480$ (1996).

15) Xin L. W., Martinerie C., Zumkeller W., Westphal M., Perbal B., Clin. Mol. Pathol., 49, M91-M97 (1996).

16) Fu M., Zhang J., Zhu X., Myles D. E., Willson T. M., Liu X., Chen Y. E., J. Biol. Chem., 276, 45888-45894 (2001).

17) Holmes A., Abraham D. J., Sa S., Shiwen X., Black C. M., Leask A., J. Biol. Chem., 276, 10594-10601 (2001).

18) Attisano L., Wrana J. L., Curr. Opin. Cell Biol., 12, 235-243 (2000).

19) Massagué J., Wotton D., EMBO J., 19, 1745-1754 (2000).

20) Berger S. L., Felsenfeld G., Mol. Cell, 8, 263-268 (2001).

21) Decker C. J., Parker R., Trends Biochem. Sci., 19, 336-340 (1994).

22) Kozak M., Annu. Rev. Cell Biol., 8, 197-225 (1992).

23) McKeown M., Annu. Rev. Cell Biol., 8, 133-155 (1992).

24) Gottesfeld J. M., Melander C., Suto R. K., Raviol H., Luger K., Dervan P. B., J. Mol. Biol., 309, 615-629 (2001).

25) Gottesfeld J. M., Belitsky J. M., Melander C., Dervan P. B., Luger K., J. Mol. Biol., 321, 249-263 (2002).

26) Shinohara K., Narita A., Oyoshi T., Bando T., Teraoka H., Sugiyama H., J. Am. Chem. Soc., 126, 5113-5118 (2004). 